\title{
An introductory analysis as to the influence of lower-body power on multidirectional speed in collegiate female rugby players
}

\author{
Robert G. LOCKIE ${ }^{1,2} \bullet$ Ashley J. ORJALO ${ }^{1}$ Victoria L. AMRAN ${ }^{1} \bullet$ \\ DeShaun L. DAVIS ${ }^{1}$ Fabrice G. RISSO ${ }^{1}$ Farzad JALILVAND ${ }^{1}$
}

\begin{abstract}
This study investigated relationships between lower-body power, measured by a vertical jump (VJ) and standing broad jump (SBJ), with multidirectional speed in collegiate female rugby players. The rugby player data was compared to that of general team sport athletes to ascertain whether there were characteristics specific to collegiate rugby players. Multidirectional speed was measured by a 20 -meter $(\mathrm{m})$ sprint $(0-5,0-10,0-20 \mathrm{~m}$ intervals) and 505 change-of-direction speed test. Eight rugby players and eight team sport athletes completed all tests. Spearman's correlations calculated relationships between the VJ and SBJ with the speed tests, and stepwise multiple regressions determined whether the jump tests predicted speed performance $(p \leq 0.05)$. For the rugby players, the VJ correlated with the $0-20 \mathrm{~m}$ interval $(\mathrm{r}=-0.73)$. The SBJ correlated with the $0-5$ and $0-10 \mathrm{~m}$ intervals, and the left-leg 505 ( $\mathrm{r}=-0.71$ to -0.88 ), and predicted $0-5 \mathrm{~m}$ and left-leg 505 time $\left(r^{2}=0.50-0.58\right)$. For the team sport athletes, only the VJ correlated with leftleg $505(\mathrm{r}=-0.80)$, and predicted left- and right-leg 505 times $\left(\mathrm{r}^{2}=0.61-0.69\right)$. The results suggest that horizontal power measured by a SBJ has a greater contribution to multidirectional speed in collegiate female rugby players.
\end{abstract}

Keywords: vertical countermovement jump; standing broad jump; linear speed; change-of-direction speed; female team sports

\footnotetext{
${ }^{1}$ Department of Kinesiology, California State University, Northridge, Northridge, USA.

${ }^{2}$ Exercise and Sport Science Department, School of Environmental and Life Sciences, University of Newcastle, Ourimbah, Australia.
} 
An introductory analysis as to the influence of lower-body power

on multidirectional speed in collegiate female rugby players

\section{Introduction}

Women's rugby union, or rugby as it is commonly called, has been recognized as an emerging sport by the National Collegiate Athletic Association (NCAA) in the USA (NCAA, 2015), which should increase the potential for greater institutional support and opportunities for collegiate female players. Accordingly, it is important for rugby and strength and conditioning coaches to understand the characteristics of their players, as this information can drive their training practices. An example of an important physical trait for rugby players is lower-body power (Argus et al., 2012; Barr et al., 2014; Gamble, 2004; Hene et al., 2011).

Lower-body power is a foundation for faster running speeds in athletes (Barr et al., 2014; de Lacey et al., 2014; Delaney et al., 2015; Lockie et al., 2011). A further consideration for rugby players is that they need to be fast in multiple directions. Multidirectional speed encompasses both linear and change-ofdirection (COD) speed (Lockie et al., 2012c). Linear speed involves straightline sprinting; COD speed combines the ability to accelerate and decelerate rapidly, and change direction, which is a component of agility (Young and Farrow, 2006). Lower-body power is often extrapolated through performance in jump tests (Meylan et al., 2009). Although jumping does not provide a direct measure of power, jump assessments are easy to administer by a coach, and they provide a valid assessment of an athlete's physical capacity (Burr et al., 2007). The relationship between jump tests and speed has been investigated within the literature. The general consensus is that athletes with better jump performance, and by extension greater lower-body power, will tend to be faster in multidirectional speed tests (Delaney et al., 2015; Lockie et al., 2012a; Lockie et al., 2011; Sierer et al., 2008).

An issue with much of this research, however, is that they involved only male participants. Gender can influence a number of physiological and biomechanical attributes, including strength and power, movement technique, muscle activation patterns, and anatomy (e.g. Q-angle, femoral notch width) (Grandstrand et al., 2006; Hart et al., 2007; Hewett et al., 2006; Spiteri et al., 2014a). The relationships between leg power, as measured through tests such as the vertical countermovement jump (VJ) and standing broad jump (SBJ) could vary in a specific female population such as collegiate rugby players. By extension, this would also influence how lower-body power could interact with multidirectional sprinting. For example, Nimphius et al. (2010) found that better VJ performance in elite female softballers did not relate to faster linear speed as measured by a 10-meter $(\mathrm{m})$ and $17.9-\mathrm{m}$ sprint, or COD speed measured by the 505 test. In contrast, Barnes et al. (2007) found that VJ height did relate to 
faster COD speed measured by a test featuring four 5 -m sprints with three $180^{\circ}$ turns in collegiate female volleyball players. Clearly there is conjecture in the literature as to how lower-body power could influence multidirectional speed in female athletes.

There should also be specific analysis of female rugby players due to the different nature of this sport compared to other popular collegiate sports for females (e.g. basketball, volleyball, softball, and soccer) (Cheslock, 2008). Although there are some similarities between these sports (i.e. the predominance of low-intensity activities such as walking and jogging, which are interspersed with high-intensity actions like running, sprinting, and sport-specific tasks), the sport-specific tasks for rugby are more novel (Suarez-Arrones et al., 2014; Virr et al., 2014). Rugby is a full-contact, collision sport, where the ball is contested via tackling, rucking, and mauling. Gamble (2004) has noted the importance of the forceful, triple extension action of the legs in contesting and retaining possession in rucks and mauls, as well as the high-power actions required in jumping and tackling. The structure of the game could also influence the importance of lower-body power in rugby players (e.g. a greater need for horizontal power development), especially when compared to other team sport athletes. This, however, requires further investigation.

Therefore, the purpose of this study was to provide an introductory investigation of the relationships between lower-body power, as measured by VJ height and SBJ distance, with multidirectional speed in collegiate female rugby players. Multidirectional speed was measured by a 20-m sprint (Gabbett, 2007; Lockie et al., 2015), while COD speed was measured by the 505 test (Gabbett, 2007; Lockie et al., 2015; Nimphius et al., 2010). In addition to this, the results from the rugby players were compared to a cohort of general team sport athletes of a similar age to ascertain whether the influence of lower-body power varied across different populations. It was hypothesized that better performance in the VJ and SBJ would relate to faster performance in the multidirectional speed tests for both the rugby players and team sport athletes. However, the results would demonstrate that horizontal power as measured by the SBJ would be particularly important for rugby players.

\section{Methods}

\section{Participants}

Eight collegiate female rugby players (age $=21.50 \pm 1.77$ years; height $=1.60$ $\pm 0.06 \mathrm{~m}$; body mass $=67.57 \pm 10.49$ kilograms), and eight female recreational, college-aged team sport athletes (age $=21.00 \pm 1.20$ years; height $=1.66 \pm 0.06$ 
An introductory analysis as to the influence of lower-body power on multidirectional speed in collegiate female rugby players

$\mathrm{m}$; body mass $=64.50 \pm 4.66$ kilograms) were recruited to participate in this study. The rugby sample included five backs and three forwards. The team sport sample included three basketball players, four soccer players, and one softball player. Participants were recruited if they: (a) were 18 years of age or older; (b) were a member of the university's women's rugby team for the rugby players, or currently participated in a team sport; (c) had a training history ( $\geq$ two times per week) in rugby or team sports that extended over the previous year; (d) were currently training for rugby or their current team sport $(\geq$ three hours per week); and (e) did not have any medical conditions compromising participation in the study. All participants were familiar with the tests performed in this study. The procedures were approved by the institutional ethics committee. All participants received an explanation of the research, including the risks and benefits of participation, and written informed consent was obtained prior to testing.

\section{Procedures}

The data collected for the rugby players and team sport athletes occurred in two different locations. This led to some variation in the data collection methods for the VJ, but the procedures were consistent for all other tests. All participants refrained from intensive exercise and stimulants in the 24-hour period prior to testing. Age, height, and body mass were recorded at the start of the first (or only) testing session. The same warm-up, consisting of 10 minutes of jogging at a self-selected pace, 10 minutes of dynamic stretching, followed by practice jumps and sprints over the test distances was completed by all participants. For both the jump and speed tests, 2-3 minutes recovery was provided between each trial.

The collegiate rugby players were tested outdoors in one session on a turf field in the evening at California State University, Northridge. The rugby participants completed the 20-m sprint first, followed by the SBJ and VJ, and the 505 test was completed last. Participants wore their own cleats for the $20-\mathrm{m}$ sprint, SBJ, and 505, and their own running shoes with textured soles for the VJ test (as it was completed on a jump mat). The data collected for the team sport athletes was part of a larger study conducted at the University of Newcastle. For these participants, testing was conducted in a biomechanics laboratory, and each participant wore their own running shoes with textured soles for all tests. Two testing sessions separated by one week were used for the team sport participants, due to equipment and laboratory availabilities. The first session incorporated the $20-\mathrm{m}$ sprint, followed by the SBJ and VJ. The second session involved assessment of the 505. Subjects were assessed at the same time of day for each session. 


\section{Vertical Countermovement Jump (VJ)}

The VJ was used to indirectly measure leg power in the vertical plane. Due to the availability of different equipment, the VJ was measured by a jump mat (Just Jump, Probotics Inc., Huntsville) for the rugby participants, while a Yardstick device (Swift Performance Equipment, Wacol, Australia) was used for the team sport participants. Although this was not ideal, concessions were made to the procedures used in an attempt to maintain some uniformity with data collection. With regards to the rugby players, the participants initially stood on the jump mat keeping their heels on the floor, before completing a countermovement and jumping as high as possible. No preparatory step was used, and no restrictions were placed on the knee angle attained during the eccentric phase of the jump. Participants were also free to swing their arms during jump, to more closely match what is required in a VJ measured with a Yardstick. Participants were instructed to maintain straight legs during the flight, before landing on both feet with flexion of the hips, knees, and ankles. Within the software for the mat, jump height was calculated from flight time via the following equation: Jump Height $=\left(1 / 2 \times\right.$ acceleration due to gravity $\left[-9.81 \mathrm{~m} \cdot \mathrm{s}^{2}\right] \times[$ total flight time $\div 27^{2}$ ). Calculation of jump height using projectile motion equations has been used in previous research (Lockie et al., 2011).

As stated, a Yardstick device measured jump performance for the team sport athletes. For this assessment, the participants stood side-on to the Yardstick (on the participants' dominant side), and while keeping their heels on the floor, reached upward to displace as many vanes as possible. The last vane moved was recorded as the standing reach height. The VJ involved the participant jumping as high as possible using a two-foot take-off with no preparatory step, with no restrictions placed on countermovement range of motion. Height was recorded in centimeters $(\mathrm{cm})$ from the highest vane moved, and vertical jump height was calculated by subtracting the standing reach height from the jump height. This value was then converted into meters. Regardless of the protocol used, each participant completed three trials, and the average was used for analysis.

\section{Standing Broad Jump (SBJ)}

The SBJ was used to indirectly measure leg power in the horizontal plane, and was performed according to established methods for all participants (Lockie et al., 2012a; Lockie et al., 2015). The participant placed the toes of both feet on the back of the starting line, and with a simultaneous arm swing and crouch, then jumped forward as far forward as possible, ensuring a two-footed landing. Participants had to 'stick' the landing for the trial to be counted. If not, the trial was disregarded and another completed. No restrictions were placed on body 
An introductory analysis as to the influence of lower-body power on multidirectional speed in collegiate female rugby players

angles attained during the preparatory phase of the jump, or the degree of arm swing used. Distance was measured using a standard tape measure, which was the perpendicular line from the front of the start line to the posterior surface of the back heel at the landing. Three trials for the SBJ were completed, with the average used for analysis.

\section{0-m Sprint}

20-m sprint time was recorded by a timing lights system (Fusion Sports, Coopers Plains, Australia) for all participants. Gates were positioned at $0 \mathrm{~m}, 5$ $\mathrm{m}, 10 \mathrm{~m}$, and $20 \mathrm{~m}$, to measure the $0-5 \mathrm{~m}, 0-10 \mathrm{~m}$, and $0-20 \mathrm{~m}$ intervals. The 0-5 $\mathrm{m}$ and 0-10 $\mathrm{m}$ intervals measure acceleration (Lockie et al., 2011). The 0-10 and $0-20 \mathrm{~m}$ intervals have also been used to assess speed in female rugby league players (Gabbett, 2007), which is a similar population to rugby players. Gate height was set at $1.2 \mathrm{~m}$, and width at $1.5 \mathrm{~m}$. Participants began the sprint from a standing start $50 \mathrm{~cm}$ behind the start line to trigger the first gate. Once ready, participants started in their own time, and were instructed to run maximally once they initiated their sprint. Participants completed three trials, and the average time for each interval was used for analysis. If the participant rocked backwards or forwards prior to starting, the trial was disregarded and repeated. Time for each interval was recorded to the nearest $0.001 \mathrm{~s}$.

\section{COD Speed Test}

The 505 was selected as the COD assessment in this study due to its common use in team sport athlete assessment (Farrow et al., 2005; Gabbett, 2007; Lockie et al., 2013a; Maio Alves et al., 2010; Nimphius et al., 2010), and that it can isolate the COD ability for each leg (Gabbett, 2007; Lockie et al., 2015; Nimphius et al., 2010). The 505 was structured as per established methods (Draper and Lancaster, 1985), with one timing gate (Figure 1). During the warm-up, participants familiarized themselves with the movement patterns required for the 505, and used a standing start. The participants sprinted through the timing gate to the turning line, indicated by a line marked on the field and markers. Participants were to place either the left or right foot, depending on the trial, on the line and turn $180^{\circ}$, before sprinting back through the gate. Three trials were recorded for turns off the left and right foot, the order of which was randomized amongst the participants. Gate height was set at $1.2 \mathrm{~m}$, with a width of $1.5 \mathrm{~m}$, and time was recorded to the nearest $0.001 \mathrm{~s}$. If the participant changed direction before hitting the turning point, or turned off the incorrect foot, the trial was disregarded and reattempted. The average time was calculated for each leg from the three trials. 


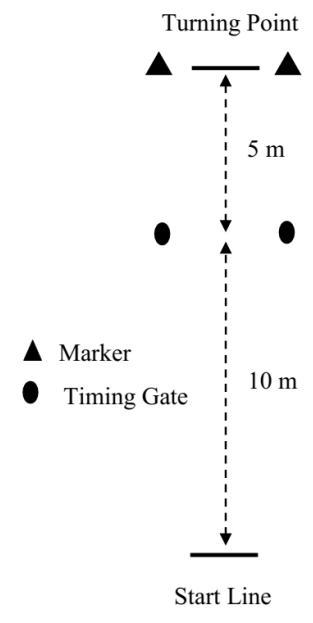

Figure 1: Structure and dimensions of the traditional 505 change-ofdirection speed test. $\mathrm{m}=$ meters.

To further isolate COD ability, the COD deficit (CODD) was also used in this study. As stated by Nimphius et al. (2013), the CODD documents the effect that one directional change can have on running when compared to a pure linear sprint over an equivalent distance. Thus, the CODD for the 505 for each leg was calculated through the formula: average 505 time - average 10-m time (Nimphius et al., 2013). The average $10-\mathrm{m}$ time was taken from the 20 -m sprint.

\section{Statistical Analysis}

All statistics were computed using the Statistics Package for Social Sciences Version 22.0 (IBM, Armonk, United States of America). Descriptive statistics (mean \pm standard deviation; $95 \%$ confidence intervals) were used to profile each variable. Due to the sample size, performance test data distribution was checked with Q-Q plots and the Shapiro-Wilk test. A one-way analysis of variance was used to compare the jump and speed tests data for the rugby and team sport groups, with significance set at $\mathrm{p} \leq 0.05$. Effect sizes (Cohen's d) were also calculated for the between-group comparisons, where the difference between the means was divided by the pooled standard deviations (Cohen, 1988). For the purpose of this research, 0.19 or less was considered a trivial effect; 0.20 to 0.59 a small effect; 0.60 to 1.19 a moderate effect; 1.20 to 1.99 a large effect; 2.00 to 3.99 a very large effect; and 4.00 and above an extremely large effect (Hopkins, 2004). 
Similar to previous team sport athlete research and due to the sample size (Lockie et al., 2015), Spearman's correlations ( $\mathrm{p} \leq 0.05$ ) computed relationships between the jump and speed tests separately for the rugby player and team sport athlete groups. The correlation coefficient strength was designated as per Hopkins (2009). A rho ( $\rho$ ) value between 0 to 0.3 , or 0 to -0.3 , was small; 0.31 to 0.49 , or -0.31 to -0.49 , moderate; 0.5 to 0.69 , or -0.5 to -0.69 , large; 0.7 to 0.89 , or -0.7 to -0.89 , very large; and 0.9 to 1 , or -0.9 to -1 , near perfect for predicting relationships. Stepwise multiple regression analyses $(\mathrm{p} \leq 0.05)$ were conducted for the $0-5 \mathrm{~m}, 0-10 \mathrm{~m}$, and $0-20 \mathrm{~m}$ sprint intervals, 505 for each leg, and CODD for each leg (each acted as a dependent variable), with the VJ and SBJ. This determined whether the jumps could predict performance in the particular multidirectional speed test.

\section{Results}

There were no significant differences in age $(p=0.44 ; d=0.33)$, height $(p$ $=0.08 ; d=1.00)$, or body mass $(p=0.47 ; d=0.38)$ between the rugby player and team sport athlete groups. In addition to this, there were no significant between-group differences in any of the jump or multidirectional speed tests (Table 1). Table 2 displays the correlation data for both the rugby players and team sport athletes. All significant relationships were negative, indicating that a better jump performance related to a faster multidirectional speed test time. With regards to the rugby players, the $\mathrm{VJ}$ had very large relationships with the $0-10 \mathrm{~m}$ and $0-20 \mathrm{~m}$ intervals from the $20-\mathrm{m}$ sprint. There were also very large relationships between the SBJ and the $0-5 \mathrm{~m}$ and $0-10 \mathrm{~m}$ intervals from the $20-\mathrm{m}$ sprint, as well as the left-leg 505. There was only one significant correlation for the team sport athletes, with a very large relationship found between the VJ and left-leg 505. 


\begin{tabular}{|c|c|c|c|c|c|}
\hline & $\begin{array}{l}\text { Rugby Players } \\
(\mathrm{n}=8)\end{array}$ & $\begin{array}{l}\text { Team Sport Athletes } \\
(\mathrm{n}=8)\end{array}$ & $p$ & $d$ & $d$ Strength \\
\hline VJ (m) & $\begin{array}{l}0.42 \pm 0.06 \\
(0.37-0.47)\end{array}$ & $\begin{array}{l}0.42 \pm 0.04 \\
(0.39-0.46)\end{array}$ & 0.86 & 0.00 & Trivial \\
\hline $\mathrm{SBJ}(\mathrm{m})$ & $\begin{array}{l}1.77 \pm 0.18 \\
(1.63-1.92)\end{array}$ & $\begin{array}{l}1.73 \pm 0.18 \\
(1.58-1.88)\end{array}$ & 0.67 & 0.22 & Small \\
\hline $0-5 \mathrm{~m}(\mathrm{~s})$ & $\begin{array}{l}1.200 \pm 0.058 \\
(1.151-1.248)\end{array}$ & $\begin{array}{l}1.194 \pm 0.053 \\
(1.150-1.239)\end{array}$ & 0.83 & 0.09 & Trivial \\
\hline $0-10 \mathrm{~m}(\mathrm{~s})$ & $\begin{array}{l}2.046 \pm 0.097 \\
(1.965-2.127)\end{array}$ & $\begin{array}{l}2.027 \pm 0.074 \\
(1.965-2.089)\end{array}$ & 0.85 & 0.22 & Small \\
\hline $0-20 \mathrm{~m}(\mathrm{~s})$ & $\begin{array}{l}3.530 \pm 0.227 \\
(3.340-3.720)\end{array}$ & $\begin{array}{l}3.510 \pm 0.125 \\
(3.406-3.615)\end{array}$ & 0.65 & 0.11 & Trivial \\
\hline 505 Left (s) & $\begin{array}{l}2.742 \pm 0.174 \\
(2.596-2.887)\end{array}$ & $\begin{array}{l}2.625 \pm 0.060 \\
(2.575-2.676)\end{array}$ & 0.10 & 0.90 & Moderate \\
\hline CODD Left (s) & $\begin{array}{l}0.696 \pm 0.165 \\
(0.558-0.834)\end{array}$ & $\begin{array}{l}0.598 \pm 0.071 \\
(0.539-0.658)\end{array}$ & 0.15 & 0.77 & Moderate \\
\hline 505 Right (s) & $\begin{array}{l}2.704 \pm 0.073 \\
(2.643-2.765)\end{array}$ & $\begin{array}{l}2.660 \pm 0.065 \\
(2.605-2.714)\end{array}$ & 0.21 & 0.65 & Moderate \\
\hline CODD Right (s) & $\begin{array}{l}0.659 \pm 0.119 \\
(0.559-0.758)\end{array}$ & $\begin{array}{l}0.632 \pm 0.099 \\
(0.550-0.714)\end{array}$ & 0.63 & 0.25 & Small \\
\hline
\end{tabular}

Table 1: Performance data (mean \pm standard deviation; 95\% confidence intervals) for the vertical jump (VJ), standing broad jump (SBJ), 20-meter (m) sprint $(0-5 \mathrm{~m}, 0-10 \mathrm{~m}$, and $0-20 \mathrm{~m}$ intervals), 505 change-of-direction speed test with turns from the left and right leg, and the change-of-direction deficit (CODD) for the left and right legs, in collegiate female rugby players, and recreational female team sport athletes. $\mathrm{s}=$ seconds; $\mathrm{p}=$ significance; $\mathrm{d}=$ effect size. 
An introductory analysis as to the influence of lower-body power on multidirectional speed in collegiate female rugby players

\begin{tabular}{|c|c|c|c|c|c|c|c|c|}
\hline & & $0-5 \mathrm{~m}$ & $0-10 \mathrm{~m}$ & $0-20 \mathrm{~m}$ & $505 \mathrm{~L}$ & CODDL & $505 \mathrm{R}$ & CODDR \\
\hline \multicolumn{9}{|c|}{ Rugby Players } \\
\hline \multirow{2}{*}{ VJ } & $\varrho$ & -0.60 & -0.84 & -0.73 & -0.50 & -0.07 & -0.30 & 0.11 \\
\hline & $\mathrm{p}$ & 0.12 & $0.01 *$ & $0.04 *$ & 0.20 & 0.87 & 0.47 & 0.80 \\
\hline \multirow{2}{*}{ SBJ } & $\varrho$ & -0.88 & -0.79 & -0.31 & -0.71 & -0.38 & -0.02 & 0.24 \\
\hline & $\mathrm{p}$ & $<0.01 *$ & $0.02 *$ & 0.46 & $0.05^{*}$ & 0.35 & 0.96 & 0.57 \\
\hline \multicolumn{9}{|c|}{ Team Sport Athletes } \\
\hline \multirow{2}{*}{ VJ } & $\varrho$ & -0.06 & -0.22 & -0.70 & -0.80 & -0.08 & -0.67 & 0.10 \\
\hline & $\mathrm{p}$ & 0.89 & 0.61 & 0.06 & $0.02 *$ & 0.84 & 0.07 & 0.82 \\
\hline \multirow{2}{*}{ SBJ } & $\varrho$ & -0.02 & -0.24 & -0.60 & -0.41 & -0.19 & -0.24 & 0.19 \\
\hline & $\mathrm{p}$ & 0.96 & 0.57 & 0.12 & 0.32 & 0.65 & 0.57 & 0.65 \\
\hline
\end{tabular}

* Significant $(\mathrm{p} \leq 0.05)$ relationship between variables.

Table 2: Spearman's correlations ( $\rho$ ) between the vertical (VJ) and standing broad jump (SBJ), and 0-5 meter (m), 0-10 m, and 0-20 m sprint intervals; 505 change-of-direction speed test with turns from the left $(\mathrm{L})$ and right $(\mathrm{R})$ leg; and the change-of-direction deficit (CODD) for the left and right legs, in

collegiate female rugby players, and recreational female team sport athletes. $\rho=$ Spearman's rho; $\mathrm{p}=$ significance.

There were only two multidirectional speed tests that had a predictive relationship with the jump tests for both the rugby and team sport groups (Table 3). For the rugby players, there was 50\% explained variance between the SBJ and 0-5 $\mathrm{m}$ time, and 58\% explained variance between the SBJ and left-leg 505 time. With regards to the team sport athletes, the VJ explained $69 \%$ and $61 \%$ of the variance for the left- and right-leg 505 time, respectively. 


\begin{tabular}{lccc}
\hline Best Jump Predictor of the Speed Test & $\mathrm{r}$ & $\mathrm{r}^{2}$ & Significance \\
\hline $\begin{array}{l}\text { Rugby Players } \\
0-5 \mathrm{~m}\end{array}$ & & & \\
$\begin{array}{l}\text { Standing Broad Jump } \\
\text { 505 Left }\end{array}$ & 0.74 & 0.50 & 0.04 \\
Standing Broad Jump & 0.76 & 0.58 & 0.03 \\
$\begin{array}{l}\text { Team Sport Athletes } \\
\text { 505 Left }\end{array}$ & & & \\
Vertical Jump & 0.83 & 0.69 & 0.01 \\
$\begin{array}{l}\text { 505 Right } \\
\text { Vertical Jump }\end{array}$ & 0.78 & 0.61 & 0.02 \\
\hline
\end{tabular}

Table 3: Stepwise linear regression analysis between vertical and standing broad jump, and selected speed tests $(0-5 \mathrm{~m}[\mathrm{~m}]$ interval in a $20-\mathrm{m}$ sprint, 505 change-of-direction speed tests with turns from the left and right leg) that demonstrated significant predictive relationships in collegiate female rugby players, and recreational female team sport athletes.

\section{Discussion}

This study provided an introductory analysis as to the influence of lower-body power, measured by the VJ and SBJ, on multidirectional speed in collegiate female rugby players. This was contrasted to an analysis of a sample of similar-aged female team sport athletes to ascertain whether vertical (VJ) or horizontal power (SBJ) was relatively more important for rugby players compared to athletes from other sports. The mean age, height, and body mass were similar between the two groups, although there was a moderate effect $(\mathrm{d}=1.00)$ for the difference in height (the team sport sample was taller). This may have been due to the presence of three basketball players in this group, as these athletes tend to be taller when compared to players from other team sports (Bayios et al., 2006; Drinkwater et al., 2008). Nevertheless, there were also no significant differences between the rugby and team sport groups in the jump and multidirectional speed tests (Table 1). This occurred even with the different methods used to measure VJ, and the different locations for data collection for each group. Although there did seem to be moderate effects for the differences in the left-leg 505, left-leg CODD, and right-leg 505 (the rugby players were slower), none of these differences were significant. This could have been influenced by the different testing locations (i.e. a turf field vs. a concrete 
An introductory analysis as to the influence of lower-body power on multidirectional speed in collegiate female rugby players

laboratory floor). Regardless, it can be assumed that the participants from each group in this study were physically similar.

There were relatively few significant correlations between the jump and speed tests for both the rugby and team sport groups, which is not atypical for this type of analysis (Lockie et al., 2014; Lockie et al., 2011; McCurdy et al., 2010; Meylan et al., 2009). Nonetheless, there were still some interesting results. For the team sport group, there was only one significant relationship, between the VJ and left-leg 505 (Table 2). The VJ was also the involved in both predictive relationships for this group (left- and right-leg 505; Table 3). The mix of athletes in this group (three basketball players, four soccer players, and one softball player) could have influenced these results. Indeed, the importance of vertical jumping in both basketball (Ziv and Lidor, 2009) and soccer (Haugen et al., 2012; Sedano et al., 2009) would have had some effect. Nonetheless, given the importance of sprint acceleration for all team sport athletes (Lockie et al., 2011), and the corresponding need for horizontal power (Brughelli et al., 2011; de Lacey et al., 2014; Lockie et al., 2012b), it was noteworthy that the SBJ did not significantly correlate with nor predict any of the multidirectional speed tests for the team sport athlete group. This was not the case for the rugby players.

There were five significant correlations for the rugby group, which was in line with the hypotheses for this study. The VJ correlated with the 0-10 and 0-20 m sprint intervals, while the SBJ correlated 0-5 m, 0-10 m, and left-leg 505 (Table 1). These results could be expected. Longer distance sprints (i.e. $20 \mathrm{~m}$ and above) place greater stress on the stretch-shortening capacities of the lowerbody muscles (Kraemer et al., 2000), and the relative contribution of the vertical component of ground reaction force will increase as an athlete progresses over a sprint (Lockie et al., 2013b). This provides some evidence as to why there were relationships between the VJ and speed over $10 \mathrm{~m}$ and $20 \mathrm{~m}$. More notable, however, are the relationships between the SBJ and multidirectional speed for the collegiate female rugby players.

Better performance in the SBJ has been linked to faster linear sprint performance over distances of less than $30 \mathrm{~m}$ in male and female track sprinters (Baker and Bell, 1994), and greater horizontal power has been associated with improvements in linear sprints over 5-20 $\mathrm{m}$ in male team sport athletes (Lockie et al., 2012b). Taken together with the results from this study, greater horizontal power as measured by the SBJ provides some influence over faster running speed over the $0-5 \mathrm{~m}$ and $0-10 \mathrm{~m}$ sprint intervals in female rugby players. Further to this, a COD speed test that features a greater linear sprint distances places a greater emphasis on linear running speed (Nimphius et al., 2013; Sayers, 2015). As the 505 features two linear $5 \mathrm{~m}$ sprints interspersed around the COD, this 
may illustrate why there was a relationship between the SBJ and left-leg 505. In addition to the significant correlations, the SBJ also predicted the $0-5 \mathrm{~m}$ sprint and left-leg 505 as well. As stated, horizontal power is important for rugby players not just during sprinting, but also in rucking, mauling, and tackling (Gamble, 2004). The nature of rugby places as emphasis on horizontal power development during sport-specific actions, which also appears to have some transfer to multidirectional speed in collegiate female players.

Despite these significant results, this study also highlights some of the limitations associated with the use of correlations analyses. As previously acknowledged, there were only a five significant correlations combined between the two groups (Table 2). Factors such as participant body mass, physique, flexibility, movement technique, and leg strength can have an effect on the statistical models derived from correlations (Brughelli et al., 2008). This is particularly relevant when considering the CODD for both legs, and the rightleg 505. Previous research has shown that an effective COD is dependent on the interplay between upper- and lower-body kinematics, ground kinetics, and physiological factors such as strength and power (Spiteri et al., 2013; Spiteri et al., 2015; Spiteri et al., 2014b). Indeed, the primary reason Nimphius et al. (2013) designed the CODD was to better isolate COD ability without the influence of linear sprinting speed. The results from this study provide support to the assertions of Nimphius et al. (2013), as the VJ and SBJ did not relate to the CODD for the rugby players or team sport athletes. This suggests a different measure of COD performance for the CODD when compared to the total 505 time (Nimphius et al., 2013). Furthermore, the 505 results highlighted that each leg should be considered specifically when analyzing COD ability. There were significant relationships for both groups with the left-leg 505 (rugby players = SBJ; team sport athletes $=\mathrm{VJ}$ ), but not for the right leg. Indeed, Lockie et al. (2014) has demonstrated that power measured via unilateral jumping for each leg can exhibit different relationships with multidirectional speed measured by a 20 -m sprint, 505, and modified T-test in male team sport athletes. An avenue for future research in collegiate female rugby players is to investigate the COD characteristics of each leg.

There are other limitations that should be acknowledged. The sample size of rugby players and team sport athletes for each group was small $(\mathrm{n}=8)$, although this did provide for an introductory analysis of collegiate female rugby players. Given that this research currently does not exist, despite the popularity of women's rugby within the US college system (NCAA, 2015), this is an important first step in investigating this sport. Nevertheless, future research should incorporate larger numbers, and players from different levels of play (e.g. 
collegiate vs. international rugby players). This study only utilized the bilateral versions of the VJ and SBJ. As better unilateral VJ and SBJ performance has been found to relate to faster 20-m sprint, 505, and T-test performance in male team sport athletes (Lockie et al., 2014), this would be worth investigating in collegiate female rugby players. Lateral jumps were also not used in this research, due to time constraints with the rugby players. Future research should incorporate lateral jumps in the analysis of women's rugby players, as superior performance in these jumps has also been related to faster multidirectional speed (Lockie et al., 2014). Nevertheless, within the context of the study limitations, this initial exploratory investigation has indicated the importance of horizontal power, as measured by the SBJ, for collegiate female rugby players.

\section{Conclusions}

In conclusion, the results from this study suggest that horizontal power, as measured by a SBJ, contributes to multidirectional sprinting in collegiate female rugby players. The nature of rugby, which requires horizontal power for rucking, mauling, and tackling, could have influenced the relative importance of this variable. This contrasted the sample of the female team sport athletes from this study, who exhibited some relationship between the VJ with multidirectional sprinting, but no relationships with the SBJ. The practical application of the findings from this research for rugby and strength and conditioning coaches is that they should ensure their athletes can demonstrate appropriate horizontal power to potentially contribute to faster multidirectional sprinting.

\section{Acknowledgements}

We would like to acknowledge our participants for their contribution to the study. Thanks to coach Adriana Conrad-Forrest for helping facilitate this research, and Samuel Callaghan, Matthew Jeffriess, Corrin Jordan, and Tawni Luczo for assisting with the data collection for the team sport athletes. This research project received no external financial assistance. None of the authors have any conflict of interest. 


\section{References}

Argus, C. K., Gill, N. D., Keogh, J. W. (2012). Characterization of the differences in strength and power between different levels of competition in rugby union athletes. Journal of Strength and Conditioning Research, 26: 2698-2704.

Baker, J. S., Bell, W. (1994). Anaerobic performance and sprinting ability in elite male and female sprinters. Journal of Human Movement Studies, 27: 235-244.

Barnes, J. L., Schilling, B. K., Falvo, M. J., Weiss, L. W., Creasy, A. K., Fry, A. C. (2007). Relationship of jumping and agility performance in female volleyball athletes. Journal of Strength and Conditioning Research, 21: 1192-1196.

Barr, M. J., Sheppard, J. M., Agar-Newman, D. J., Newton, R. U. (2014). Transfer effect of strength and power training to the sprinting kinematics of international rugby players. Journal of Strength and Conditioning Research, 28: 2585-2596.

Bayios, I. A., Bergeles, N. K., Apostolidis, N. G., Noutsos, K. S., Koskolou, M. D. (2006). Anthropometric, body composition and somatotype differences of Greek elite female basketball, volleyball and handball players. Journal of Sports Medicine and Physical Fitness, 46: 271-280.

Brughelli, M., Cronin, J., Chaouachi, A. (2011). Effects of running velocity on running kinetics and kinematics. Journal of Strength and Conditioning Research, 25: 933-939.

Brughelli, M., Cronin, J., Levin, G., Chaouachi, A. (2008). Understanding change of direction ability in sport. Sports Medicine, 38: 1045-1063.

Burr, J. F., Jamnik, V. K., Dogra, S., Gledhill, N. (2007). Evaluation of jump protocols to assess leg power and predict hockey playing potential. Journal of Strength and Conditioning Research, 21: 1139-1145.

Cheslock, J. (2008). Who's Playing College Sports? Money, Race and Gender. http://files.eric.ed.gov/fulltext/ED539973.pdf.

Cohen, J. (1988). Statistical Power Analysis for the Behavioral Sciences (2nd ed.). Hillsdale, New Jersey: Lawrence Earlbaum Associates. 
An introductory analysis as to the influence of lower-body power on multidirectional speed in collegiate female rugby players

de Lacey, J., Brughelli, M. E., McGuigan, M. R., Hansen, K. T. (2014). Strength, speed and power characteristics of elite rugby league players. Journal of Strength and Conditioning Research, 28: 2372-2375.

Delaney, J. A., Scott, T. J., Ballard, D. A., Duthie, G. M., Hickmans, J. A., Lockie, R. G., Dascombe, B. J. (2015). Contributing factors to change-ofdirection ability in professional rugby league players. Journal of Strength and Conditioning Research, 29: 2688-2696.

Draper, J. A., Lancaster, M. G. (1985). The 505 test: a test for agility in the horizontal plane. Australian Journal of Science and Medicine in Sport, 17: 15-18.

Drinkwater, E. J., Pyne, D. B., McKenna, M. J. (2008). Design and interpretation of anthropometric and fitness testing of basketball players. Sports Medicine, 38: $565-578$.

Farrow, D., Young, W., Bruce, L. (2005). The development of a test of reactive agility for netball: a new methodology. Journal of Science and Medicine in Sport, 8: $52-60$.

Gabbett, T. J. (2007). Physiological and anthropometric characteristics of elite women rugby league players. Journal of Strength and Conditioning Research, 21: 875-881.

Gamble, P. (2004). Physical preparation for elite-level rugby union football. Strength and Conditioning Journal, 26: 10-23.

Grandstrand, S. L., Pfeiffer, R. P., Sabick, M. B., DeBeliso, M., Shea, K. G. (2006). The effects of a commercially available warm-up program on landing mechanics in female youth soccer players. Journal of Strength and Conditioning Research, 20: 331-335.

Hart, J. M., Garrison, J. C., Kerrigan, D. C., Palmieri-Smith, R., Ingersoll, C. D. (2007). Gender differences in gluteus medius muscle activity exist in soccer players performing a forward jump. Research in Sports Medicine, 15: 147155.

Haugen, T. A., Tonnessen, E., Seiler, S. (2012). Speed and countermovementjump characteristics of elite female soccer players, 1995-2010. International Journal of Sports Physiology and Performance, 7: 340-349. 
Hene, N. M., Bassett, S. H., Andrews, B. S. (2011). Physical fitness profiles of elite women's rugby union players. African Journal for Physical, Health Education, Recreation and Dance, Supplement: 1-8.

Hewett, T. E., Ford, K. R., Myer, G. D., Wanstrath, K., Scheper, M. (2006). Gender differences in hip adduction motion and torque during a single-leg agility maneuver. Journal of Orthopaedic Research, 24: 416-421.

Hopkins, W. G. (2004). How to interpret changes in an athletic performance test. Sportscience, 8: 1-7.

Hopkins, W. G. (2009). A scale of magnitude for effect statistics. www.sportsci.org/resource/stats/index.html.

Kraemer, W. J., Ratamess, N. A., Volek, J. S., Mazzetti, S. A., Gómez, A. L. (2000). The effect of the Meridian shoe on vertical jump and sprint performances following short-term combined plyometric/sprint and resistance training. Journal of Strength and Conditioning Research, 14: 228-238.

Lockie, R. G., Callaghan, S. J., Berry, S. P., Cooke, E. R., Jordan, C. A., Luczo, T. M., Jeffriess, M. D. (2014). Relationship between unilateral jumping ability and asymmetry on multidirectional speed in team-sport athletes. Journal of Strength and Conditioning Research, 28: 3557-3566.

Lockie, R. G., Callaghan, S. J., Jeffriess, M. D. (2013a). Analysis of specific speed testing for cricketers. Journal of Strength and Conditioning Research, 27: 2981-2988.

Lockie, R. G., Jeffriess, M. D., Schultz, A. B., Callaghan, S. J. (2012a).

Relationship between absolute and relative power with linear and change-ofdirection speed in junior American football players from Australia. Journal of Australian Strength and Conditioning, 20: 4-12.

Lockie, R. G., Murphy, A. J., Knight, T. J., Janse de Jonge, X. A. K. (2011). Factors that differentiate acceleration ability in field sport athletes. Journal of Strength and Conditioning Research, 25: 2704-2714.

Lockie, R. G., Murphy, A. J., Schultz, A. B., Jeffriess, M. D., Callaghan, S. J. (2013b). Influence of sprint acceleration stance kinetics on velocity and step kinematics in field sport athletes. Journal of Strength and Conditioning Research, 27: 2494-2503. 
An introductory analysis as to the influence of lower-body power on multidirectional speed in collegiate female rugby players

Lockie, R. G., Murphy, A. J., Schultz, A. B., Knight, T. J., Janse de Jonge, X. A. K. (2012b). The effects of different speed training protocols on sprint acceleration kinematics and muscle strength and power in field sport athletes. Journal of Strength and Conditioning Research, 26: 1539-1500.

Lockie, R. G., Schultz, A. B., Callaghan, S. J., Jordan, C. A., Luczo, T. M., Jeffriess, M. D. (2015). A preliminary investigation into the relationship between functional movement screen scores and athletic physical performance in female team sport athletes. Biology of Sport, 32: 41-51.

Lockie, R. G., Schultz, A. B., Jeffriess, M. D., Callaghan, S. J. (2012c). The relationship between bilateral differences of knee flexor and extensor isokinetic strength and multi-directional speed. Isokinetics and Exercise Science, 20: 211-219.

Maio Alves, J. M., Rebelo, A. N., Abrantes, C., Sampaio, J. (2010). Short-term effects of complex and contrast training in soccer players' vertical jump, sprint, and agility abilities. Journal of Strength and Conditioning Research, 24: 936941.

McCurdy, K. W., Walker, J. L., Langford, G. A., Kutz, M. R., Guerrero, J. M., McMillan, J. (2010). The relationship between kinematic determinants of jump and sprint performance in division I women soccer players. Journal of Strength and Conditioning Research, 24: 3200-3208.

Meylan, C., McMaster, T., Cronin, J., Mohammad, N. I., Rogers, C., Deklerk, M. (2009). Single-leg lateral, horizontal, and vertical jump assessment: reliability, interrelationships, and ability to predict sprint and change-ofdirection performance. Journal of Strength and Conditioning Research, 23: 11401147.

NCAA. (2015). Emerging Sports for Women. from http://www.ncaa.org/about/resources/inclusion/emerging-sports-women.

Nimphius, S., Geib, G., Spiteri, T., Carlisle, D. (2013). "Change of direction" deficit measurement in Division I American football players. Journal of Australian Strength and Conditioning, 21: 115-117.

Nimphius, S., McGuigan, M. R., Newton, R. U. (2010). Relationship between strength, power, speed, and change of direction performance of female softball players. Journal of Strength and Conditioning Research, 24: 885-895. 
Sayers, M. G. L. (2015). The influence of test distance on change of direction speed test results. Journal of Strength and Conditioning Research, 29: 2412-2416.

Sedano, S., Vaeyens, R., Philippaerts, R. M., Redondo, J. C., Cuadrado, G. (2009). Anthropometric and anaerobic fitness profile of elite and non-elite female soccer players. Journal of Sports Medicine and Physical Fitness, 49: 387-394.

Sierer, S. P., Battaglini, C. L., Mihalik, J. P., Shields, E. W., Tomasini, N. T. (2008). The National Football League Combine: performance differences between drafted and nondrafted players entering the 2004 and 2005 drafts. Journal of Strength and Conditioning Research, 22: 6-12.

Spiteri, T., Cochrane, J. L., Hart, N. H., Haff, G. G., Nimphius, S. (2013). Effect of strength on plant foot kinetics and kinematics during a change of direction task. European Journal of Sport Science, 13: 646-652.

Spiteri, T., Hart, N. H., Nimphius, S. (2014a). Offensive and defensive agility: a sex comparison of lower body kinematics and ground reaction forces. Journal of Applied Biomechanics, 30: 514-520.

Spiteri, T., Newton, R. U., Binetti, M., Hart, N. H., Sheppard, J. M., Nimphius, S. (2015). Mechanical determinants of faster change of direction and agility performance in female basketball athletes. Journal of Strength and Conditioning Research, 29: 2205-2214.

Spiteri, T., Nimphius, S., Hart, N. H., Specos, C., Sheppard, J. M., Newton, R. U. (2014b). Contribution of strength characteristics to change of direction and agility performance in female basketball athletes. Journal of Strength and Conditioning Research, 28: 2415-2423.

Suarez-Arrones, L., Portillo, J., Pareja-Blanco, F., Saez de Villareal, E., SanchezMedina, L., Munguia-Izquierdo, D. (2014). Match-play activity profile in elite women's rugby union players. Journal of Strength and Conditioning Research, 28 : 452-458.

Virr, J. L., Game, A., Bell, G. J., Syrotuik, D. (2014). Physiological demands of women's rugby union: time-motion analysis and heart rate response. Journal of Sports Sciences, 32: 239-247.

Young, W., Farrow, D. (2006). A review of agility: practical applications for strength and conditioning. Strength and Conditioning Journal, 28: 24-29. 
An introductory analysis as to the influence of lower-body power on multidirectional speed in collegiate female rugby players

Ziv, G., Lidor, R. (2009). Physical attributes, physiological characteristics, oncourt performances and nutritional strategies of female and male basketball players. Sports Medicine, 39: 547-568.

Robert LOCKIE, $\mathrm{PhD}$, is currently an assistant professor in biomechanics and strength and conditioning at California State University, Northridge. Robert earned his PhD, in which he investigated sprint acceleration technique, and speed, strength, and power training in field sport athletes, at the University of Technology, Sydney. Since this time, Robert has conducted research into linear speed, change-of-direction speed, and agility; sprint technique; sports biomechanics; team sport analysis; and strength and conditioning.

\section{Corresponding Author}

Dr. Robert Lockie

California State University, Northridge

Department of Kinesiology

18111 Nordhoff Street

Northridge, CA 91330 USA

Phone (international): +1 818-677-6983

Fax (international): +1 818-677-3207

Email: robert.lockie@csun.edu

Ashley ORJALO has recently completed her undergraduate degree in Kinesiology majoring in Exercise Science at California State University, Northridge. She was recently accepted into the Masters of Strength and Conditioning program at California State University, Fullerton, and will commence this year. Ashley has conducted research into team sports, strength and conditioning, and post-activation potentiation in sprinting.

Victoria AMRAN has recently completed her undergraduate degree in Kinesiology majoring in Exercise Science at California State University, Northridge. She will be applying to Medical School in pursuit of surgery over the coming year. Victoria has recently been added to the research team focusing on oncology treatment at the University of Southern California.

DeShaun DAVIS has recently completed his undergraduate degree in Kinesiology majoring in Applied Fitness at California State University, Northridge. He will be applying to a Masters program in strength and conditioning in the coming year. DeShaun has conducted research into team sports, strength and conditioning, and post-activation potentiation in sprinting. 
Fabrice RISSO has recently completed his undergraduate degree in Kinesiology majoring in Applied Fitness at California State University, Northridge. He will be applying to a Masters program in strength and conditioning in the coming year. Fabrice has conducted research into team sports, strength and conditioning, and post-activation potentiation in sprinting.

Farzad JALILVAND is currently the strength and conditioning coach at Granada Hills Charter High School in Los Angeles, and also lectures in kinesiology at California State University, Northridge. He completed his Masters in exercise physiology at California State University, Northridge, and has conducted research in soccer and team sport performance. 
